\title{
Application of Wireless Communication Tools in Managing Construction Projects
}

\author{
Lingaraj.K \\ Department CSE, \\ R.Y.M.E.C, Bellary, \\ Karnataka, India.
}

\author{
Nagaveni.V.Biradar \\ Department CSE, \\ R.Y.M.E.C, Bellary, \\ Karnataka, India.
}

\author{
Girisha.H \\ Department CSE, \\ R.Y.M.E.C, Bellary, \\ Karnataka, India.
}

\begin{abstract}
Many Different organizations utilize Wireless Communication technology such as social media to transfer information for many different purposes and most especially to add value to their business. Some of these communication media are mostly used currently for marketing purposes and getting for company's name out through advertising via social networking sites such as Face Book and MySpace Whistle others use social media like Twitter to engage with a large audience of 'followers' who willing to read brief messages sent which often include link to more depth article or advertising campaign. The aim of the research project is to develop a methodological wireless communication framework that can be used in construction operations. A combination of case study, structured interview and questionnaire were used to gather data. The questionnaire was administrated randomly to ten small and medium sized construction firms and one main contractor all working on the on-going large construction project. The result of this result showed that this form of communication technology would enhance better communication within the construction organization supply chain by allowing team members and members of the public to the construction process and to the construction operations. This medium form of communication is rich in information and may influence how construction on site is carried out.
\end{abstract}

\section{Keywords}

Wireless Communication Tools, Social media, Construction project, Building Integrated Modeling

\section{INTRODUCTION}

Social media is a modern form of wireless communication tool made possible with successful merger of the World Wide Web (Internet) and mobile technologies (cellular communication technology). It is a medium that allows for instant communication and is now seen as a popular mode of communication acceptable to all forms of commerce and industry. Wireless communication technologies have become a very useful tool to construction companies. In the late 1990 's firms began exchange and post information on internet systems but with little opportunity for human interaction (Wilkinson, 2010), as shown in figure 1 .

Public projects blogs can be used to find out peoples ' opinions on the projects during construction phase management can respond to these in the correct manner and deal with issues to uphold their public image. Another method of involving the public, as well as company executives, is providing links with in the blog to video feeds showing the progression of the construction.

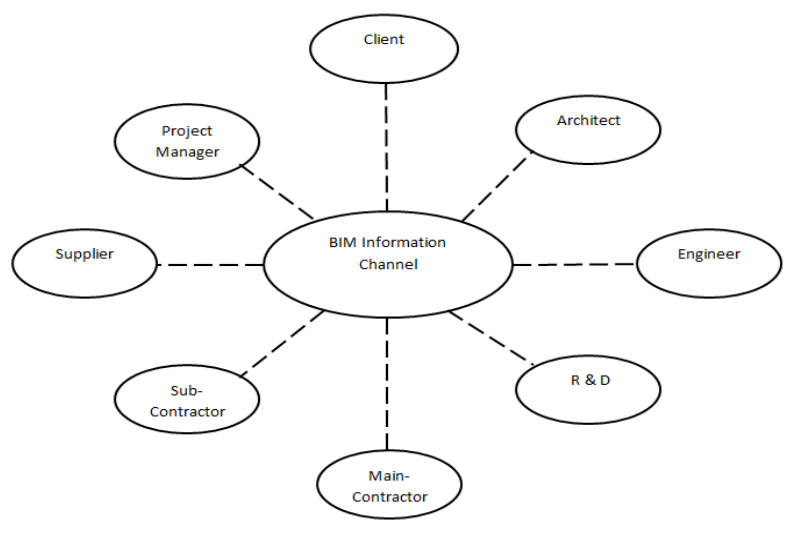

Figure 1: Limited information exchange through intranet system

In the modern society people has the ability to share information or collaboration from any one from around the globe using wireless communication based social media. Kaplan and Haenlein (2010, p61) define social media as "a group of inter-based applications that build on ideological and technological foundations of web 2.0 and that allow the creation and exchange of user generated content".

Social media has introduced substantial and pervasive changes to communication between organization, communities, and individuals. This present challenges for firms, as many established management methods are ill-suited to deal with customers and employees who no longer want to be talked at but want firms to listen, appropriately engage, and respond (Kietzmann, Hermkens, McCarthy \& Sivestre 2011). Construction Organizations therefore must use this wireless Communication technology to their best advantage to engage with their world outside the organization.

Organization can use for example, social media to build an online identity. Many organizations now a days use social media to connect with others, build brand awareness, and increase firm's visibility. In current economic climate companies also try to identify ways in which they can profitable use of application such as Twitter, LinkedIn, Squidoo, Facebook, Blog, Flicker, YouTube as thy are increasingly becoming an integral part of good marketing campaigns and marketing strategy. Furthermore it opens new marketing channels, and niche verticals that would be costprohibitive to target via other marketing or media (Brown and Reuhl, 2011) 
Social Media and particularly social networking websites are universally being used by diverse industries ranging from entertainment and education to marketing and finance (Billingsley, 2011). In the built environment, on the other hand, the concept the concept of using social media in a manner beneficial to the industry is relatively new. Construction firms generally are not an early adopter of new technologies and as not an early adopter of new technologies and as a result construction companies have been slow to exploit social tool in their businesses (Butcher, 2011) . Many construction companies are simply not aware of the advantages and opportunities that social media can bring to their business.

This paper presents a research project on the development of a methodological wireless communication framework that can be used during construction operations. It also discusses the possible opportunities that portals like Facebook or Twitters can bring to construction companies. As Social Media became an everyday part of life and a natural extension of all people social life, organizations like construction industry cannot ignore it and should use in a manner beneficial to the built environment.

\section{RELATED WORK}

In the research work carried out by (Mohammed 2011) on Social media, it was identified that many UK construction firms are using social media to connect with their audience online however these communication channels are not being presently used to the most beneficial manner. They are mainly used for marketing purpose and for getting company's name out through advertising. Blogs for example would be valuable tool when conducting feasibility studies as it enable the client to gain options and suggestions from public regarding the proposed development. Sheridan(2010) in his study suggested the blogging would be of particular interest to contractors or client wanting to accentuate corporate social responsibility.

Henry and Kato (2008) identified YouTube and skype as an excellent visual communication medium for use in construction, You Tube mainly enhances construction as it can provide training videos which in turn means cheaper, easier, faster learning tools for individuals on site. Visual learning has provided very effective in construction industries. There are some instances in the large projects where there is scope for a video link to be incorporated on construction website to watch buildings (for example) being erected from start to finish. Skype for example is used for video conference tool, for the people around the country or the world that can only chat through the skype tool. That has been founded by (Herring, Scheidt, Wright, Bonus, 2005) to be effective in construction, not only when it is used in this instance but also to interview the people from around the world. This has meant constructions companies save a great amount of time and money completing this process. This is widely used today in hiring the people around the world. Offsite project meetings can incur large travelling expenses; it is more time and cost effective to make internet video calls using wireless communication tools such as skype. Firms can use micro blogs like Twitter to post company updates and any one registered as the following the company updates and anyone registered as the following companies kept in loop applications for twitter are also available and can be used to circulate information that is put out Smartphone applications for twitter are also available and can be used to circulate information to staff members through text based posts of up to 140 characters knows as "Tweets" ( Mashable, 2011) this could also be used by suppliers to tweet site management information regarding expected and unexpected delivery times for examples.

Table 1 shows some key UK, construction firms that use social media. A construction project, typically, consists of a multi-disciplinary team. With the construction firm representing a fair proportion of the team. With such diversity there is a requirement that communication between the numerous stakeholders should be effective and efficient and social media is an effective business communication resource to achieve this. The enhancement of communication on site possible through smart phone applications such as procore for the iphone as it can allow for easy circulation of documents such as health \& safety policies and risk assessments to staff that have such a phone (Procore Technologies Inc, 2011).

Table 1: Top UK Construction Company uses Social Media

\begin{tabular}{|c|c|}
\hline SL.NO & Construction Company \\
\hline 1 & 4Projects \\
\hline 2 & AceCad Software \\
\hline 3 & Bentley Systems Inc \\
\hline 4 & Causeway Technologies \\
\hline 5 & RedSky IT \\
\hline 6 & Woobius \\
\hline 7 & C \\
\hline
\end{tabular}

\section{RESARCH DESGIN AND METHODOLOGY}

The pilot survey was administrated to randomly selected ten small and medium (SME'S) contractors and one large construction firm working on an on-going large construction project and took two months to complete. A combination of case study and questionnaire was used in this research project. Four structured interviews of sixty minutes in length were conducted with IT managers from the main contractor's organization responsible for this project. Recording were made of the four interviews which were transcribed. Each interview was conducted to the organization office ranging from system requirements, usage, training, operations, and technology. The interview where supplemented by structured questionnaire. The questionnaire were designed with flexibility to allow the respondents to give their views at the end of the survey to discuss any additional information related implementation and operation of social media in the organization. They were emailed out to IT managers of these construction firms. The researcher was also aware of the limitations of the pre-design/ categorized questions and they may not reflect some of the construction firms 'understanding, there-fore open end questions end questions were also included in the survey where possible. The questions were designed to be short, clear and simple and simple which were nicely formatted on two pieces of A4 size paper and it was printed on light-purple coloured paper. The study by (sarantakos, 2005) argued that cover a letter, presentation of 
the questionnaire, colour of paper used and format of the questionnaire have been demonstrated to have a great effect on response rate

\section{DICUSSIONS}

The frame work profiling is shown as shown in figure 2 which is designed to facilitate the implementation of any wireless communication business information resource the twitter, and facebook in any construction business operations. The framework should be able to help any company set up a suitable social media plan. This will undoubtedly help to improve communications between the construction supply chain involved in the management and in delivery of onsite operations. The information gathered from the questionnaire, structured interviews and case study is beneficial in that it provided invaluable lunch pad for the development of the framework. This was particularly helpful in the feasibility phase and it is applied in different ways throughout the development phases. It provided information also on how these firms can get the most out the social media and will give senior management team ammunition to use for justification for the money spent during the development.

As shown in figure 2 the wireless communication framework is implemented on seven phases namely; research \& development or briefing stage; governance, decision protocol and cost analysis of alternative solutions; mobilisation; integration, evaluation of success and refinement. These various implementation phases of the social media is discussed below.

\section{Briefing Stage}

This stage involves the identification of system requirements to ensure hardware and software compatibility, faster operations, download and preliminary cost analysis. The development time frame including the identification of suitable case studies for implementation should also be considered at this stage. The faster rate of evaluation of both hardware and software necessary for Twitter and Facebook implementation for example would require the definition of an implementation deadline. Delayed implementation may result in technological obsolescence. The implementation time frame may need to take account of existing service contract renewals. This stage is critical to the successful implementation of twitter or Facebook as a communication tool. The login account, password, security, ethics agreement, company's code of conduct must be discussed, agreed and signed off by all parties concerned. Failure joining the company's stage to obtained feedback, or asks questions from the staff member or supply chain. Some people may fell communication tool and it is important to allay any doubts or fears that may be held by staff members at this stage.

Capabilities should include photos, videos and documents, such as Healthy and Safety videos, latest issue drawings, instructions to subroutines, order confirmations, weekly and daily work schedules. This can be done using either Facebook or Twitter add-on application called TwitDec (Twi5.com, 2012). It should be useable with many smart phones, Pc, ipad or tablet with relevant connection.

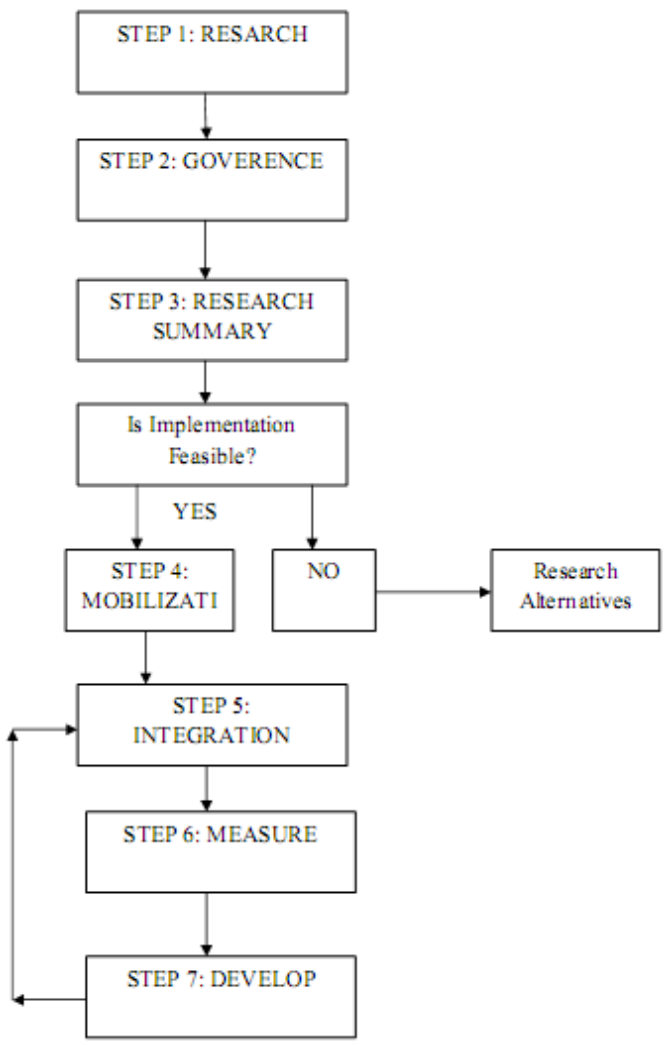

Figure 2: Frame work for the implementation of a wireless communication technology of a typical construction company

\section{Governance}

This phase involves the identification of risks and uncertainties in the proposed wireless communication medium and control procedures to put in place to manage them. The risks must be understood in detail and where possible removed or controlled by setting clear policies within the business. Any remaining risks can then be balanced against the potential rewards. If the remaining risk is perceived to be too great, it may be decided not to proceed with in project.

Unsuitable, un-vetted Tweets for instance may be interpreted as company views rather than those expressed by an individual. Some of these risks and uncertainties might be as a result of misinterpretation of messages and short nature of twit message may need to lack of explanation and clarity. It is also vital to monitor data control procedures as documents could be accidentally sent to be larger number of users (Hall 2009) and mechanism of dealing with reduced productivity if usage not controlled. Policies will need to be set up to ensure all output on Twitter or Facebook for example is sent only to the intended parties and also the content is suitable and relevant. Commercially sensitive information must be protected by appropriate measures. This could be achieved by restricting access to conversations and designating specific feeds, to individuals. Vetting of feeds which are intended to be public may be necessary (Naylor 2007). By introducing smart phones and internet connectivity to an increased number of employees control measures must be put in place so that this is not be abused and used personal rather than company use. There is also the risk of reduced employee productivity due to time wasted surfing the internet which must be controlled. 


\section{Decision Protocol}

This will involve the confirmation whether the implementation of the technology will be feasible. Where the costs of implementation are prohibitive or the projected level of communication increase cannot be effectively managed, then other solutions must be sought. However, where it is decided to go ahead, then practical issues surrounding mobilization must be tacked.

\section{Mobilization}

Here roles and responsibilities must be clearly defined for all staff involved. Training and help facilities will be provided to enable both internal and external users use the smart phones, hardware and software system correctly and able to understand and how the social media operates and the way in which they are expected to use it for managing project information for instance. Also, those in the supply chain must be advice on the level of relevant training is required for their staff. The training will also involve communicating policies and control measures and educating staff on appropriate use and the consequences of unauthorized use.

\section{Integration}

The Integration of the communication technology in any business venture would require a greater understanding of the most efficiently ways to use the communication technology whilst at the same time maximizing its benefits. Identifying the internal champions who are already potential users of say Twitter is a key success. These users can apply their own knowledge whilst studying the success/failure in other businesses to push new ideas and embrace enterprising tactics that ensure the continued development of the company's use a Twitter. The champions can only remain innovative when give the appropriate level of support, resources, training and open-mindedness from senior employees feeling uninspired to find innovative ways to improve it use. Transparency with regards to Twitter or Facebook use for instance is paramount as it allows the development of stronger, more direct relationships with the supply chain, however it can also lead to the leaking of sensitive information through misuse (Dupont, 2012).

\section{Evaluation}

The success of the social media has to be measured in order to ensure the targets that met. This would involve the measurement of productivity levels, smart wireless communication technology usage and rework levels to find any reductions and in turn, cost savings can be used to provide benchmark against which the future improvements can be referenced. A quarterly report on the effectiveness of social media within the construction company can then be prepared for their senior executives to ensure their support is continued.

\section{Refinement}

It is imperative that use of any wireless communication technology meets the growing need of the modern construction industry. Identifying new areas of the business to incorporate it use is necessary, following its success in other operations. Update and changes of the software are inevitable at some stages as this evolution brings along new threats, meaning the company must constantly re-evaluate their policies, strategies and also conduct risks assessments (Roman 2011). Keeping abreast of development in wireless communication methods and other types of software ensure development within the company remains in the loop of social media. The company also needs a proactively update their knowledge on wireless technological advancement to ensure they can complete against companies that they do. It is likely that in near future Building Information Modeling (BIM) will become the preferred method for storing and sharing project drawings and documentation. It will be essential to ensure that the social media communication medium selected can be made compatible with the BIM software.

\section{CONCULISION}

This paper as discussed the development of a wireless communication framework for construction work operations. This success of any construction project is highly dependent on the smooth transfer of information during the various stages of construction processes. Construction firms are responsible for managing the construction process on a building site and should aware of the significance and growing importance of wireless communication tools, both in personal lives and in the organization.

Social media enhances better communication within the construction firm by allowing works to contribute their views on the host of issue related to the construction process and to construct firm. This form of Feedback is rich in information and may, for example, influence how construction works carried out.

Construction firms should encourage their workers to embrace this type of wireless communication medium as it empowers and can liberate the worker's voice, and the mind-set of the construction firm. There is a greatest potential for the construction firm who decides to be earlier adopter of social media and current modern technologies. They will have a competitive advantage on the rival firms who may still embrace the traditional communication methods of the managing constructions projects from previous century.

The next phase of this research project will focus on full evaluation of the operational working of the framework using construction case studies. The research will also explore how to build safe guards for the protection of the construction firms from external and internal threats. It is vital to provide periodic reviews to avoid unsolicited. During periodic checks, messaging should be reread to make sure they contain right information.

Social medium is not passing phenomenon, but is changing the behavior and expectation of consumers and employees and there is a great potential for any business that wants to take this forward.

\section{ACKNOWLEDGMENTS}

This works was supported by the R\&D Cell of Computer Science Engineering R.Y.M.E.C, Bellary. Our sincere thanks to the coordinator of R\&D Cell, HOD of CSE, Teaching and Non-Teaching Staff Members in Department of CSE, R.Y.M.E.C, Bellary. 


\section{REFERENCES}

[1] Kaplan, M.Haenlein (2010), "Users of the world unite! The challenges \& opportunities of social media, Business Horizones", Vol 53, Issue1, p56-68.

[2] Mohamud , (2011, October 13), 5 ways construction companies can use Twitter for business. Available from: http://www.pauleycreative.co.uk/2010/10/5-waysconstruction-companies-can-use-twitter-for-business/, [Accessed 02-july-2012].

[3] Gillham, (2010), developing a Questionnaire, continuum, London.

[4] DuPont (2012), Security and transparency : How social media are transferring business, [online] http://sustinablebusinessfoura.com/securitytrnasparency-webinar?reference $=$ smt_solis, [Accessed 02-nov-2012].

[5] H. Kietzmann, J. H. Hemkens, K.Mccarly, I\& Silvestra, B. Social media ? Get serious ! Understanding the functional building blocks of social media, Business Horizons, 2011 (54), 241-251.

[6] J. Naylor (2007), Online Social Networking. The Employer's Dilemma, London Message Labs.

[7] J. Roman (2011), Social media : A Constantly Evolving Risks, [online] Available at http://www.bankingforsecurity.eu/articles.php?art_id=39 9] \&opg=1 , [Accessed 02-nov-2012].

[8] J. Sheridan (2010), To Tweet or Not to Tweet? [online] Available

http://archrecord.construction.com/practicle/business/100 4practice-2.asp[ Accessed 02-Jan-2013].

\section{AUTHOR}

Lingaraj.K received his $\mathrm{BE}$ and M.Tech Degree in Information Science Engineering and Computer Network Engineering from Visvesvaraya Technological University, Belgaum, India in 2009 and 2012. Currently working has Lecturer in Department of Computer Science and Engineering at RYMEC, Bellary. His interest includes in Energy Efficiency in Wireless Sensor Networks, Wireless Communication, Multimedia Mining in Wireless Sensor Network and Information retrieval in Mobile Computing Environment.

Nagaveni Biradar working as Associate Professor in RYMEC, Bellary in India since 2003. She obtained B.E and M.Tech degrees in Computer Science and Engineering in Gulbarga University and Visvesvaraya Technological University, Belgaum, India in 1996 and 2003 respectively. Her research lies in Data Mining, Image Processing and Wireless Communication.
[9] K. Bilingslay (2011), "Survey suggestions social media usage on the rise In IT and financial industries." Available from: http://wwww.optif.net/ social-mediausage-on-the-rise-In-IT-and -financial- industries/.

[10] Linkedin (2011), [online] available from World Wide Web. http://www.linkedin.com/home, [Accessed 02-nov2012].

[11] M.Henry, Y. Kato (2008), "A social networking based approach to information management in construction", Serisan ken Keyu: 60(3), 175-179.

[12] N.Brown, B.Reuhl (2004), linkdin/facebook/twitter from http://www.slidershare.net/construction market/linkedinfacebook-twitter-best-practices-for construction-markets.

[13] N. Mashable (2004), "What is Twitter?" , [online] available from World Wide Web: http://mashable.com/what-is-twitter/.

[14] P. patel (2010), "How are the top 15 construction companies using social media?". Available from: http://www.pauleycreative.co.uk/2010/06/ How-are-thetop-15-construction-companie- using-social-media.

[15] Pwikinson 9210) social media (web 2.0) in the construction industry [online] available from World Wide Web: http:// www.slidershare.net/EEP paul/ socialmedia- in-the-construction-industry/.

[16] Procare Technologies Inc 2011, procore for iphone [online] available from World Wide Web: http://itunes.apple.com/us/procore-for iphone/id=374930542? $\mathrm{mt}=8$.

Girisha.H working as Associate Professor in RYMEC, Bellary in India since 2001.He obtained B.E and M.Tech degrees in Computer Science and Engineering and Software Engineering in Gulbarga University and Visvesvaraya Technological University, Belgaum, India in 1997 and 2001 respectively. He currently work has Head of Department in Computer Science and Engineering Bellary. His research lies in Image Processing using Artificial Intelligence, Information Retrieval and Multimedia Mining in Wireless Sensor Network. 